
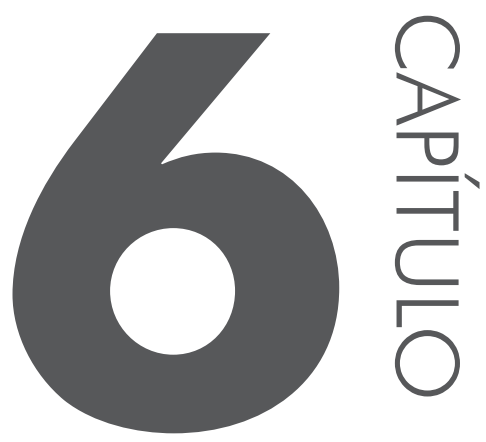

\title{
ANÁLISE SENSORIAL DE PRODUTOS ELABORADOS À BASE DE PARTES NÃO CONVENCIONAIS DE FRUTAS
}

Caroline de Oliveira Galindo Juliany Piazzon Gomes Ana Flavia de Oliveira

\section{INTRODUĈ̣̃O}

Partes não convencionais de alimentos são aquelas que geralmente não são consumidas e, portanto, são descartadas, como as cascas, os talos e as sementes. Se a população brasileira fosse orientada quanto à forma de consumo dessas partes, a ingestão de vitaminas e minerais do brasileiro aumentaria, reduzindo a fome e melhorando sua qualidade alimentar. 
Dessa forma, objetivou-se levantar receitas que aproveitassem as cascas de melancia, melão e banana, que habitualmente são descartadas, testando sua aceitação, além de verificar as características nutricionais dessas receitas. Ao final, as receitas aprovadas foram distribuídas por meio de folder à comunidade participante do Centro de Convivência da Terceira Idade da Zona Leste de Londrina, para divulgar o aproveitamento integral desses alimentos.

\section{APROVEITAMENTO INTEGRAL DE ALIMENTOS}

O aproveitamento integral de alimentos tem como função aproveitar as partes que normalmente são descartadas (OLIVEIRA et al., 2002). Com ele, há a possibilidade de reduzir os custos na preparação de receitas e diminuir o desperdício dos alimentos, além de aumentar seu valor nutricional.

Uma pesquisa envolvendo mais de mil pessoas feita pelo Instituto Akatu sobre o consumo consciente dos brasileiros mostrou que mais da metade da população não consome totalmente o alimento (MATTAR, 2006). A falta de informação faz com que ocorra um desperdício de toneladas de alimentos que poderiam ser consumidos.

Mundialmente, são descartados mais de $30 \%$ dos alimentos que poderiam ser consumidos devido às deficiências no sistema de colheita, transporte e armazenagem, além da comercialização. As partes não convencionais dos alimentos, como os talos e cascas, são consideradas tão nutritivas quanto as que são consumidas (IBGE, $2005^{1}$ apud NUNES; BOTELHO, 2009). A maioria das alternativas, como criação de receitas contendo tais partes de frutas e hortaliças, visam ajudar no combate à fome, desnutrição e desperdício, sendo consideradas de baixo custo (SOUZA et al., 2006).

As cascas das frutas descartadas por várias famílias apresentam uma quantidade maior de nutrientes em relação às partes normalmente consumidas. Seu consumo pode ajudar, também, na diminuição do desperdício e ser uma fonte alternativa de nutrientes (GONDIM et al., 2005). O aproveitamento integral dos alimentos, além de ter baixo custo na preparação e aumentar o valor nutricional, ajuda no aumento do rendimento da refeição. Ao reduzir a perda dos alimentos, pode-se aumentar sua disponibilidade (GAVA, $1984^{2}$ apud NUNES; BOTELHO, 2009).

O desperdício de alimentos pode ser relacionado com o meio ambiente, pois, quando estes são descartados de forma errônea, provocam resultados irreversí-

1 IBGE - INSTITUTO BRASILEIRO DE GEOGRAFIA E ESTATÍSTICA. Indicadores Agropecuários 1996-2003. Rio de Janeiro, mar. 2005.

2 GAVA, A. J. Princípio de Tecnologia de Alimentos. São Paulo: Nobel, 1984. 
veis, como a produção do chorume que é contaminante para os rios. Reduzindo o desperdício de alimentos, reduzem-se os impactos ambientais, tornando o meio ecologicamente mais equilibrado (SANTOS, 2008).

O Brasil é um país rico quanto à variedade de frutas, verduras e legumes que, com a ajuda de um ótimo clima e solo, permitem que as plantas cresçam saudáveis e nutritivas desde as suas folhas, cascas, sementes, polpa e até as raízes. No entanto, é considerado o país do desperdício. Isso se deve pelas setenta mil toneladas de alimentos que são jogadas no lixo diariamente. Cerca de um quarto de toda a produção de frutas é descartado. Alguns dados mostram que o desperdício alimentar chegaria a ser o suficiente para alimentar 19 milhões de pessoas com três refeições ao dia (HARDISSON et al, 2001³ apud MONTEIRO, 2009).

$\mathrm{O}$ aproveitamento integral de alimentos, além de ajudar a população a reduzir o custo das preparações, pode auxiliar na redução de doenças que podem ser decorrentes da inapropriada ingestão de alimentos, como obesidade e desnutrição. A importância na utilização de cascas de frutas se dá pela diminuição dos gastos com alimentação, além da melhoria na qualidade nutricional das preparações e na redução do desperdício de alimentos, tornando possível a criação de novas receitas. São muitas as frutas que sofrem grandes perdas, como o abacate $(31 \%)$, a banana (40\%) e o morango (39\%) (EMBRAPA, $2009^{4}$ apud STORCK, 2013).

A utilização das partes não convencionais seria uma das maneiras de evitar o desperdício. Porém, há poucos estudos abordando tal tema. Assim, as informações de valor nutricional dos alimentos são poucas, havendo a utilização mínima destes, com baixo aproveitamento integral e grande desperdício (GONDIM et al., 2005).

Há a possibilidade de se incrementar a culinária diária com a utilização integral dos alimentos, proporcionando uma alimentação mais rica em fibras, vitaminas e minerais. Para que haja uma utilização correta, é necessário ter conhecimento da composição centesimal desses alimentos. Existem vários estudos comparando as partes consumidas com as não convencionalmente consumidas dos alimentos, e muitos deles mostram que os nutrientes são amplamente encontrados nas partes que normalmente são descartadas (STORCK, 2013).

Não é novidade que as frutas e legumes têm um alto valor nutricional. O que não era conhecido é que as cascas, talos e folhas de alguns desses alimentos possuem nutrientes, como carboidratos, cálcio, vitamina $\mathrm{C}$ e fibras, em quantidades

3 HARDISSON, A. et al. Mineral composition of the banana (Musa acuminata) from the island of Tenerife. Food Chemistry, Tenerife, v. 73, p. 153-161, 2001.

4 EMBRAPA - EMPRESA BRASILEIRA DE PESUISA AGROPECUÁRIA. O papel dos bancos de alimentos na redução do desperdício de alimentos. set. 2007. Disponível em: <http://www.mds. gov.br>. Acesso em: 12 jun. 2016. 
maiores do que as partes consumíveis. A vitamina C é um dos nutrientes que mais tem importância no organismo das pessoas. Sua falta causa distúrbios neurológicos, dores musculares, entre outras doenças. Tem a função de neutralizar a ação dos radicais livres, além de moléculas relacionadas ao envelhecimento e formação de tumores. Goiaba, morango e limão são exemplos de frutas com altos níveis dessa vitamina. A polpa da banana superou todas as demais frutas, mas casca da banana possui o dobro de potássio do que aquele encontrado na polpa: na casca, há 0,9 gramas, enquanto a polpa possui 0,4 gramas desse nutriente (UNESP, 2006).

Assim, alguns talos, folhas e cascas possuem mais nutrientes do que a própria parte que normalmente é consumida. Outro exemplo é a casca de melancia. Se o consumidor soubesse que na casca é encontrado $90 \%$ do teor de fibras e potássio de toda a fruta, seria mais claro e fácil para o mesmo usá-la em alguma receita. Apesar de haver um alto teor de nutrientes nas partes não convencionais de alimentos, ainda não é normal ver nas famílias o hábito de consumi-las (MARANGONI, 2009).

A Coordenadoria de Abastecimento da Secretaria de Agricultura e Abastecimento do Estado de São Paulo avaliou que o Brasil perde, aproximadamente, $1,4 \%$ do PIB com os alimentos não aproveitados. A EMBRAPA realizou um estudo sobre o desperdício, e teve como resultado que, anualmente, cada brasileiro desperdiça cerca de 37 quilos de alimentos (UNESP, 2006).

\subsection{Consumo de frutas e hortaliças no Brasil}

Segundo dados da Pesquisa de Orçamentos Familiares (2008), no Brasil houve um aumento de 4,38 quilos no consumo anual per capita de frutas. Todas as regiões brasileiras tiveram aumento significativo no consumo per capita de frutas, sendo a região Sul a maior consumidora desse alimento, seguida pela região Sudeste. Realizando uma análise por produto, nota-se que a banana e a laranja, junto com a melancia, tiveram o maior incremento de consumo nos lares brasileiros. A banana é a fruta mais consumida no país, $7,68 \mathrm{~kg} / \mathrm{pessoa} / \mathrm{ano}$. A laranja fica em segundo lugar, com $5,44 \mathrm{~kg} /$ pessoa/ano. O crescimento da produção da fruta ajudou na ampliação de seu consumo. As frutas que são mais consumidas em lares brasileiros são, então, banana, laranja, melancia e maçã, frutas mais populares, relativamente baratas frente às demais, disponíveis durante praticamente todo o ano e encontradas na maioria dos estabelecimentos. São frutas sensorialmente aceitáveis e acessíveis a todas as classes de renda (GALESKAS et al., 2012).

No Brasil, o consumo de frutas e verduras ainda é baixo. Cerca de 2,8\% das calorias totais são consumidas, ou seja, um quarto da recomendação diária que é entre 9 e $12 \%$. O consumo de frutas e verduras é maior no meio urbano do que no meio rural ( $3,2 \%$ contra $1,8 \%$ das calorias totais, respectivamente). Porém, ainda é baixo o consumo das mesmas, comparando-se à recomendação nutri- 
cional diária para um humano. O Quadro 6.1 mostra a participação relativa de frutas e sucos naturais no total de calorias determinado pela aquisição alimentar domiciliar, por situação do domicílio (IBGE, 2010).

Quadro 6.1 Participação relativa de frutas e sucos naturais na alimentação da população brasileira

\begin{tabular}{ccc}
\hline \multirow{2}{*}{ Alimentos e grupos de alimentos } & \multicolumn{2}{c}{ Participaç̃̃o relativa (\%) } \\
\cline { 2 - 3 } & \multicolumn{2}{c}{ Situação do domićlio } \\
\cline { 2 - 3 } & Urbano & Rural \\
\hline Frutas e sucos naturais & 2,3 & 1,2 \\
Bananas & 0,9 & 0,6 \\
Laranjas & 0,3 & 0,2 \\
Outras frutas & 0,9 & 0,5 \\
Sucos naturais & 0,1 & 0,0 \\
\hline
\end{tabular}

Fonte: IBGE, Diretoria de Pesquisas, Coordenação de Trabalho e Rendimento, Pesquisa de Orçamentos Familiares 2008-2009 (Modificada).

\subsubsection{Banana}

A banana (Musa spp.), pertencente à família das Musaceae, teve sua origem no Extremo Oriente (NASCENTE et al., 2005). É a fruta mais consumida do mundo em sua forma natural e é cultivada em várias regiões por todo o Brasil (BORGES et al., 2006).

É um alimento de alto valor energético com carboidratos de fácil conversão e, apesar de pobre em proteínas e lipídeos, apresenta quantidades desses nutrientes mais elevadas do que os da maçã, pera, cereja e pêssego. Possui vitamina C, além de vitamina A e algumas do complexo B. Existe, ainda, pequena quantidade de vitamina $\mathrm{D}$ e E, e maior percentagem de minerais como fósforo, cálcio, potássio e ferro do que os presentes na maçã ou laranja (FASOLIN et al., 2007).

O principal componente da banana verde é o amido resistente. Este, nas bananas maduras, é convertido em açúcares como glicose, frutose e sacarose (FASOLIN et al., 2007). Existe uma enorme variedade de bananas. As principais e mais conhecidas são: nanica, nanicão, maçã, terra, pacovan, prata e prata-anã (BORGES et al., 2006). No Brasil, a banana, por ter baixo custo, é a fruta mais importante enquanto complemento alimentar.

\subsubsection{Melão}

O melão, pertencente à família Cucurbitaceae, é originado da África e da Ásia. Foi trazido ao Brasil pelos escravos no século XVI e novamente introduzido 
no século XIX pelos imigrantes europeus, que expandiram a produção nas regiões Sul e Sudeste (MOREIRA et al., 2013). Possui uma grande quantidade de elementos minerais, principalmente potássio, sódio e fósforo, além de algumas vitaminas (BECKER; KRÜGER, 2010).

O melão (Cucumis melo L.) é uma das hortaliças muito consumidas, com grande popularidade no mundo. Em 2005, o Brasil teve uma produção de 190 mil toneladas de melão, apresentando, então, grandes tendências de crescimento de consumo interno e exportação (VARGAS et al., 2008).

A qualidade do fruto depende de características presentas na polpa, como sólidos solúveis, aparência e "flavor", que indica a aceitabilidade do consumidor (VARGAS et al., 2008). Os principais tipos de cultivares existentes são: amarelo, cantaloupe, pele de sapo, honey dew, gália, charentais, net melon e tipo caipira (MOREIRA et al., 2013).

A variedade mais produzida e difundida no Brasil é o melão amarelo tipo valenciano, que tem origem espanhola. Possui frutos redondos, com casca amarela, uma polpa espessa e resistente ao transporte e à armazenagem. A composição de resíduos gerados do processamento dos alimentos varia muito dependendo tanto da matéria-prima como da técnica empregada da produção. Os principais resíduos do processo de melão, seja para suco ou para produtos minimamente processados, são a casca, as sementes e sobras dos cortes (MIGUEL et al., 2008).

\subsubsection{Melancia}

A melancia, classificada como Curcubita citrullus, tem sua origem na Índia e foi trazida ao Brasil pelos escravos da África tropical. O plantio é indicado no Nordeste do Brasil, devido ao baixo índice de chuva nos meses de maio a setembro. O mercado possui vários cultivares de melancia (48 variedades ao todo), que são classificadas pela sua forma, coloração, peso e tolerância a doenças. A melancia é indicada ao consumo em períodos de calor, devido ao seu alto teor de água. Após o corte, a mesma necessita de conservação em baixa temperatura sob refrigeração, envolvidas em plástico para evitar perdas e degradação. É utilizada, no Brasil, isoladamente, como sobremesa (SANTANA; OLIVEIRA, 2005).

A melancia possui baixo valor nutritivo. Sua composição é feita pelo teor de vitaminas, como a $\mathrm{C}$ e as do complexo B. A pigmentação vermelha é devida ao licopeno, um carotenoide com elevada atividade antioxidante. Seu consumo é recomendado em regimes de emagrecimento e em tratamentos que ajudam no aumento do fluxo de urina, devido à diurese que a fruta favorece. É um fruto não climatérico, que deve ser colhido maduro, pois sua qualidade não melhora após a colheita. Tamanho, cor, ressonância do fruto ao impacto e cor da zona que está em contato com o solo são alguns indicadores de colheita (ALMEIDA, 2003). 


\subsection{Valor nutricional dos alimentos}

A composição de um alimento é de extrema importância para compreender seu valor nutritivo. Essa informação tem finalidade de fornecer o controle de qualidade, a composição química e a avaliação nutricional de um alimento (CHAVES et al., 2004), correspondendo à quantidade de lipídeos, umidade, proteína bruta, fibra bruta, cinzas e carboidratos presentes em cem gramas de um alimento, que expressam seu valor nutritivo, de uma forma geral (PEREIRA, 2011).

A umidade é de fundamental importância, pois a água tem grande influência em características sensoriais como aparência, sabor, estrutura, suscetibilidade e deterioração dos alimentos. Ela solubiliza compostos importantes como vitaminas, minerais, açúcares e ácidos, além de permitir o desenvolvimento de micro-organismos que comprometem a segurança dos alimentos. A fração que corresponde aos lipídeos, além de constituir os próprios lipídeos, possui componentes lipossolúveis como vitaminas e pigmentos (PEREIRA, 2011).

A cinza de um alimento indica resíduos inorgânicos após a queima da matéria orgânica, sendo constituída principalmente de potássio, sódio, cálcio e magnésio. Os carboidratos são compostos de grande abundância em alimentos. Têm como principais funções serem nutritivos (geram energia), adoçante natural (glicose, frutose...), matéria-prima para produtos fermentados, principal ingrediente em cereais, responsáveis por propriedades reológicas em alimentos de origem vegetal e reação de escurecimento em vários alimentos (PARK; ANTÔNIO, 2006).

A proteína bruta é um grande grupo de substâncias com estruturas semelhantes que possuem, porém, diferentes funções fisiológicas. É calculada pela determinação de nitrogênio, que, por meio de um fator de conversão, transforma o resultado em proteína bruta. Já as fibras possuem uma associação de polímeros com alto peso molecular, que compreende uma estrutura de polissacarídeos vegetais (celulose, pectinas) e outros sem a referida estrutura (ligninas e gomas). A fibra bruta é constituída por componentes da parede celular dos vegetais que não são digeridos pelo organismo humano. São eles partes dos carboidratos resistentes ao tratamento sucessivo com ácido e base diluídos. O valor energético de um alimento faz referência à quantidade de calorias que o mesmo pode oferecer ao organismo, de modo que proporcione energia suficiente para as atividades diárias de um ser humano (PEREIRA, 2011).

A Ingestão Diária Recomendada (IDR) é a quantificação de vitaminas, minerais e proteínas que devem ser ingeridas durante o dia para atender às necessidades nutricionais por pessoas sadias. Para o controle da IDR, é necessária a composição proximal de alimentos, pois a mesma avalia o suprimento e o consumo alimentar de um país, verifica a adequação nutricional da dieta da população e avalia seu estado nutricional, entre outros benefícios (GONDIM; MOURA, 2005). 


\subsection{Análise sensorial de alimentos}

A Análise Sensorial é a disciplina usada para interpretar, analisar e medir as reações que são percebidas pelos sentidos humanos (tato, visão, audição, gosto e olfato) às características de alimentos e/ou materiais (ABNT, $1993^{5}$ apud FERREIRA et al., 2000). Pesquisadores buscam desenvolver algumas metodologias para que os testes e seus objetivos sejam bem definidos e que essas metodologias levem à escolha de métodos e provadores apropriados, à tratamentos estatísticos corretos e à interpretação correta de tais dados (DUTCOSKY, 1996).

Como um produto alimentício é destinado ao consumidor, sua aceitação e/ ou preferência sobre o mesmo tem total importância, pois o próprio consumidor é quem avalia tal produto. Dessa forma, a análise sensorial auxilia no elo entre consumidor e produto, proporcionando informações necessárias que irão refletir em sua posição no mercado, mostrando que não são somente características físicas, químicas e microbiológicas que dão qualidade ao produto, se o mesmo não foi aceito sensorialmente pelos consumidores (MINIM, 2010 ${ }^{6}$ apud MENDES, 2013).

Avaliar, comparar e diferenciar atributos sensoriais de um produto está no dia-a-dia das pessoas, quando as mesmas aceitam ou rejeitam um alimento, ou quando preferem alguma marca específica. A análise sensorial usa tal habilidade para avaliar produtos como alimentos e bebidas, utilizando uma metodologia aplicada aos estudos, além de tratamento estatístico apropriado ao mesmo (FERREIRA et al., 2000). Existem metodologias em análise sensorial que ajudam a avaliar os atributos. Estas podem ser divididas em três grandes grupos: testes discriminativos, testes descritivos e testes afetivos.

Os testes discriminativos são utilizados para avaliar as diferenças entre dois ou mais produtos. Os testes descritivos permitem a avaliação dos atributos sensoriais de produtos, então são empregadas equipes treinadas de provadores (BORBA, 2012). Já os testes afetivos são utilizados quando se quer saber a aceitabilidade do consumidor perante tal produto. Para esse teste, normalmente são utilizadas as escalas hedônicas que ajudam o consumidor a classificar sua amostra preferida e/ou mais bem aceita (MEILGAARD et al., $1991^{7}$ apud FERREIRA et al., 2000).

As escalas hedônicas expressam o gostar/desgostar do produto. As escalas mais usadas são as balanceadas, que possuem o mesmo número de características positivas e negativas, ao contrário das não balanceadas, que podem ter mais características positivas do que negativas (FERREIRA et al., 2000).

5 ABNT - ASSOCIAÇÃO BRASILEIRA DE NORMAS TÉCNICAS. Análise sensorial dos alimentos e bebidas: terminologia. $1993.8 \mathrm{p}$.

6 MINIM, V. P. R. Análise sensorial - Estudo com consumidores. 2. ed. Viçosa: Ed. UFV, 2010.

7 MEILGAARD, M.; CIVILE, G. V.; CARR, B. T. Sensory evaluation techniques. 2. ed. Nova York: Editora CRC Press, 1991. 354 p. 


\section{MATERIAIS E MÉTODOS}

Esta pesquisa foi realizada no período entre outubro de 2013 e maio de 2014. Trata-se de uma pesquisa bibliográfica e experimental. Levantaram-se os dados sobre as características nutricionais das frutas (partes convencionais e não convencionais) em sites científicos. Então, verificou-se a disponibilidade de receitas com as cascas do melão, da melancia e da casca de banana. As receitas foram testadas e analisadas quanto às questões nutricionais e sensoriais.

\subsection{Composição centesimal das frutas}

Os teores de carboidratos, proteínas, fibras, gorduras totais, saturadas e sódio, além do valor energético das partes comestíveis e não comestíveis da banana prata e do melão, foram retiradas da Tabela Brasileira de Composição de Alimentos (TACO, 2011) e dos artigos de Gondim et al. (2005) e Storck et al. (2013). Já para as partes da melancia, além da TACO (2011), foram utilizados dados de Almeida (2003), Santana et al. (2005) e da Universidade Estadual Paulista (UNESP, 2006).

\subsection{Desenvolvimento das formulações}

As receitas foram retiradas de sites de culinária da internet e foram testadas quanto ao preparo e à aceitação. Para cada receita, buscou-se uma preparação salgada e uma doce, conforme descritas a seguir. No desenvolvimento de cada receita, pesou-se os ingredientes secos e, depois, o rendimento final.

\subsubsection{Receitas da banana prata}

Bolo de casca de banana

Ingredientes: quatro bananas com casca, meia xícara de chá de óleo de soja, quatro ovos, duas xícaras e meia de chá de farinha de trigo, três xícaras de chá de açúcar, duas xícaras de chá de achocolato em pó.

Modo de fazer: Lave bem quatro bananas, descasque-as e corte-as em cubinhos. Reserve as cascas e a fruta picada. No liquidificador, bata meia xícara de óleo de soja, quatro ovos e as cascas até virar um creme homogêneo. Em outro recipiente, coloque duas xícaras e meia de chá de farinha de trigo, três xícaras de chá de açúcar, duas xícaras de achocolatado em pó e uma colher de canela. Misture os ingredientes secos com o creme e os pedaços da banana com as mãos. Por último, acrescente uma colher de chá de fermento em pó. Coloque a massa em uma assadeira untada e asse por quarenta minutos no forno $\left(160^{\circ} \mathrm{C}\right)$. Polvilhe com canela e açúcar antes de servir (BOL, 2014). 


\section{Farofa de casca de banana}

Ingredientes: uma xícara de chá de farinha de mandioca, uma xícara de chá de farinha de milho, cascas de três bananas, cheiro-verde a gosto, uma cebola média picada, um dente de alho grande, duas colheres de sopa de óleo, dois ovos cozidos.

Modo de preparo: Em uma panela, faça um refogado com óleo, cebola e alho. Em seguida, acrescente as cascas de banana picadas e refogue até que fiquem macias. Acrescente a farinha de mandioca e a farinha de milho, mexendo até que comece a ficar dourada. Acrescente os ovos cozidos picados e o cheiro-verde picado, misture bem (TELESSAÚDE, 2014).

\subsubsection{Receitas da melancia}

Doce da casca de melancia

Ingredientes: duas xícaras de chá de casca de melancia, uma xícara e meia de chá de açúcar, um quarto de xícara de chá de água.

Modo de preparo: Retire a casca verde da melancia e utilize a branca. Corte em cubos e reserve. Faça uma calda com o açúcar e a água. Acrescente a casca da melancia e deixe cozinhar até apurar (TUDO GOSTOSO, 2014a).

\section{Salpicão da casca de melancia}

Ingredientes: cinco xícaras de chá de casca de melancia ralada, sal a gosto, trezentos gramas de peito de frango desfiado, uma xícara e meia de chá de salsão cortado, um quarto de xícara de chá de cebola, duas colheres de sopa de salsa, um limão, meia xícara de chá de maionese.

Modo de preparo: Lave muito bem a melancia. Corte em pedaços e descasque. Rale a casca da melancia em ralo fino. Ferva as cascas raladas em água e sal, até que fiquem macias. Reserve. Cozinhe o peito de frango em água e sal, desfie e reserve. Corte em fatias o salsão e a cebola. Reserve. Pique a salsa e misture à casca de melancia ralada e aferventada, ao peito desfiado, ao salsão e à cebola. Tempere com sal, limão e acrescente a maionese. Sirva frio (TUDO GOSTOSO, 2014b).

\subsubsection{Receitas do melão}

Doce da casca do melão

Ingredientes: duas xícaras e meia de chá de casca de melão, três xícaras de chá de água, duas xícaras de chá de açúcar, três colheres de sopa de coco ralado. 
Modo de fazer: Lave bem o melão com uma escovinha. Rale a casca no ralo grosso. Junte a casca ralada com a água e o açúcar. Leve ao fogo e cozinhe até a casca ficar macia e formar uma calda em ponto de fio médio. Desligue o fogo e acrescente o coco ralado. Sirva frio (HUMANIDADE SUSTENTÁVEL, 2014).

\section{Suflê da casca do melão}

Ingredientes: Duzentos gramas de cascas de melão (quatro fatias grossas), meia cebola média picada, um dente de alho amassado, uma pitada de alecrim e manjericão frescos, uma colher de sopa de salsinha, cinco colheres de sopa de margarina, um tablete de caldo de galinha, dez colheres de sopa de farinha de trigo, três xícaras de chá de leite, dois ovos.

Modo de preparo: Refogue na margarina as cascas de melão, a cebola, o alho e as ervas bem picadas. Quando a cebola e a casca do melão estiverem transparentes, acrescente o caldo de galinha e espere derreter. Em seguida, acrescente a farinha de trigo e mexa até desgrudar da panela. Separe as gemas dos ovos e reserve as claras. Misture as gemas no leite e acrescente à mistura, mexendo até engrossar. Reserve. Bata as claras até ficarem em ponto de neve. Incorpore as claras à mistura reservada (delicadamente) e leve para assar por cerca de quarenta minutos (CODEAGRO, 2007).

\subsection{Análise sensorial}

A análise sensorial foi conduzida no Laboratório de Análise Sensorial da Universidade Tecnológica Federal do Paraná (UTFPR) - campus Londrina, no período noturno. A aplicação das formulações desenvolvidas foi conduzida em três dias, cada dia com um tipo de fruta. Aproximadamente sessenta jovens, não treinados e voluntários, participaram de cada teste. A população de provadores consistiu em alunos e professores da UTFPR - Londrina.

Para aplicação dos testes, foi disponibilizada a cada julgador uma bandeja com duas amostras das preparações (uma doce e uma salgada), um copo de água para limpeza bucal entre uma amostra e outra, e a ficha de avaliação. Foi apresentado aos julgadores um termo de consentimento livre e esclarecido, que fora devidamente preenchido e arquivado pela pesquisadora para fins de esclarecimento às questões ética da pesquisa. As amostras foram devidamente codificadas com números aleatórios, seguindo o delineamento de blocos incompletos casualizados.

Foi utilizado teste de aceitação com as formulações verificando se as mesmas seriam aceitas no mercado. A escala hedônica utilizada foi a de dez pontos, de acordo com a proposta de Villanueva (2003), conforme Figura 6.1. Para cada formulação, levantou-se os dados de cor, sabor, textura e aceitação global. Antes 
da aplicação da ficha sensorial, levantaram-se as características do consumidor provador e seu consumo das partes não convencionais das frutas analisadas.

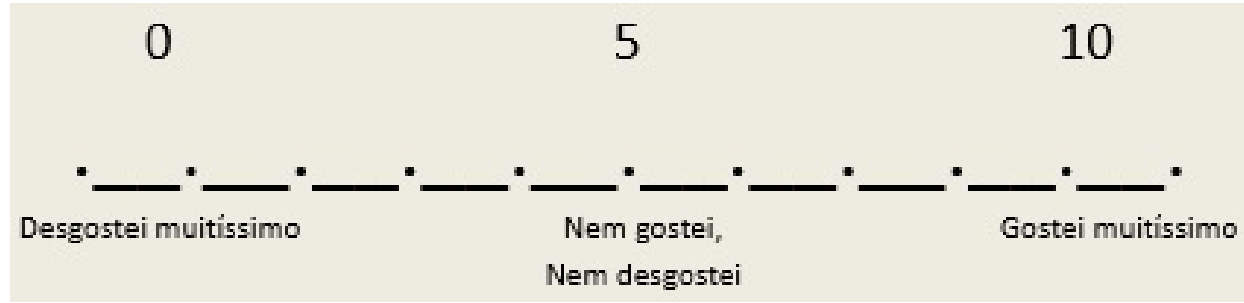

Fonte: Villanueva (2003).

Figura 6.1 Escala hedônica utilizada para o teste sensorial

Além das médias, calculou-se o Índice de Aceitabilidade (IA), valor em porcentagem que tem como objetivo obter a aceitação do produto pelos consumidores. Para o produto ser considerado como bem aceito, o valor mínimo de IA deve ser de 70\% (DUTCOSKY, 2007). Para este cálculo foi adotada a seguinte expressão matemática:

$$
\mathrm{IA}=\frac{\text { Nota obtida para a amostra } \times 100}{\text { Nota máxima da escala utilizada }}
$$

Equação 1- Expressão matemática para cálculo do índice de aceitabilidade (IA).

Para análise estatística, aplicou-se o Teste T com auxílio do software Excel for Windows ${ }^{\circledR}$, presumindo variâncias diferentes. Adotou-se o valor de p de $5 \%$ para verificar diferença sensorial entre os produtos, comparando apenas as mesmas receitas entre si.

\subsection{Informação nutricional das formulações}

A informação nutricional das formulações foi realizada a partir dos ingredientes individualmente pesados. Depois de prontas, foi pesado o rendimento das formulações. Foram conferidos os seguintes nutrientes: carboidratos, gorduras totais e saturadas, proteínas, fibras, sódio e valor energético de cada alimento em tabelas de composição de alimentos (conforme descrito no item 4.1). Pesquisou-se na RDC no 359/2003 (BRASIL, 2003a) o valor da porção de cada formulação. Esses dados foram calculados e apresentados conforme orientação da RDC no 360 de 23 de dezembro de 2003 (BRASIL, 2003b). Considerou-se o valor de gorduras trans como "zero", pois as frutas e os ingredientes utilizados não são fonte de tal nutriente. 


\subsection{Elaboração do folder}

Elaborou-se um folder simples e objetivo, com auxílio do software Word for Windows ${ }^{\circledR}$, com uma pequena explicação sobre o aproveitamento integral dos alimentos e as receitas testadas. Eles foram apresentados e entregues no Centro de Convivência da Terceira Idade da Zona Leste de Londrina.

\section{RESULTADOS E DISCUSSÃO}

Os valores encontrados nas tabelas referentes à composição centesimal de todos os alimentos não apresentaram grande diferença entre si. Os dados encontrados demonstram que o consumo de casca na alimentação traria grandes benefícios à saúde, considerando seus valores de carboidratos, proteínas, fibras e gorduras nelas presentes, conforme apresentado nas Tabelas 6.1, 6.2 e 6.3.

Tabela 6.1 Comparação das informações nutricionais da banana prata

\begin{tabular}{|c|c|c|c|c|c|c|c|}
\hline Banana Prata & kcal & $\begin{array}{c}\text { Carboidrato } \\
\text { (g) }\end{array}$ & $\begin{array}{l}\text { Profeína } \\
\text { (g) }\end{array}$ & $\begin{array}{l}\text { Gordura } \\
\text { total (g) }\end{array}$ & $\begin{array}{c}\text { Gordura } \\
\text { saturada (g) }\end{array}$ & $\begin{array}{l}\text { Fibras } \\
\text { (g) }\end{array}$ & Sódio (mg) \\
\hline \multicolumn{8}{|l|}{ Polpa } \\
\hline $\begin{array}{c}\text { GONDIM et al., } \\
2005\end{array}$ & 128 & 34 & 1 & 0 & 0 & 1,5 & $<0,4$ \\
\hline TACO, 2011 & 98 & 26 & 1,3 & 0,1 & 0 & 2 & traços \\
\hline $\begin{array}{c}\text { STORCK et al., } \\
2013\end{array}$ & 98 & 26 & 1,3 & 0,1 & 0 & 2 & $\begin{array}{c}\text { não } \\
\text { calculado }\end{array}$ \\
\hline \multicolumn{8}{|l|}{ Casca } \\
\hline $\begin{array}{l}\text { GONDIM et al., } \\
2005\end{array}$ & 35,3 & 4,91 & 1,69 & 0,99 & 0 & 1,99 & 54,27 \\
\hline $\begin{array}{c}\text { STORCK et al., } \\
2013\end{array}$ & 16,9 & 2,92 & 0,51 & 0,35 & 0 & 1 & $\begin{array}{c}\text { não } \\
\text { calculado }\end{array}$ \\
\hline
\end{tabular}

Tabela 6.2 Comparação das informações nutricionais do melão

\begin{tabular}{cccccccc}
\hline Melão & $\mathbf{k c a l}$ & $\begin{array}{c}\text { Carboidrato } \\
(\mathbf{g})\end{array}$ & $\begin{array}{c}\text { Proteina } \\
(\mathbf{g})\end{array}$ & $\begin{array}{c}\text { Gordura } \\
\text { total }(\mathbf{g})\end{array}$ & $\begin{array}{c}\text { Gordura } \\
\text { saturada }(\mathbf{g})\end{array}$ & $\begin{array}{c}\text { Fibras } \\
(\mathbf{g})\end{array}$ & Sódio (mg) \\
\hline $\begin{array}{c}\text { Polpa } \\
\text { TACO, 2011 }\end{array}$ & 29 & 7,5 & 0,7 & traços & 0 & 0,3 & 11 \\
$\begin{array}{c}\text { GONDIM et } \\
\text { al., 2005 }\end{array}$ & 29 & 8 & 1 & 0 & 0 & 0,3 & 11 \\
$\begin{array}{c}\text { STORCK et al., } \\
2013\end{array}$ & 29 & 7,5 & 0,7 & 0 & 0 & 0,3 & $\begin{array}{r}\text { não } \\
\text { calculado }\end{array}$ \\
\hline
\end{tabular}




\begin{tabular}{cccccccc}
\hline Melão & kcal & $\begin{array}{c}\text { Carboidrato } \\
(\mathbf{g})\end{array}$ & $\begin{array}{c}\text { Proteína } \\
(\mathbf{g})\end{array}$ & $\begin{array}{c}\text { Gordura } \\
\text { total }(\mathbf{g})\end{array}$ & $\begin{array}{c}\text { Gordura } \\
\text { saturada }(\mathbf{g})\end{array}$ & $\begin{array}{c}\text { Fibras } \\
(\mathbf{g})\end{array}$ & Sódio (mg) \\
\hline $\begin{array}{c}\text { Casca } \\
\text { GONDIM et al., }\end{array}$ & 18,05 & 3,05 & 1,24 & 0,1 & 0 & 1,42 & 8,54 \\
$\begin{array}{c}2005 \\
\text { STORCK et al, } \\
2013\end{array}$ & 18,9 & 2,13 & 2,03 & 0,25 & 0 & 4,58 & $\begin{array}{c}\text { não } \\
\text { calculado }\end{array}$ \\
\hline
\end{tabular}

Tabela 6.3 Comparação das informações nutricionais da melancia

\begin{tabular}{|c|c|c|c|c|c|c|c|}
\hline Melancia & kcal & $\begin{array}{c}\text { Carboidrato } \\
\text { (g) }\end{array}$ & $\begin{array}{l}\text { Proteína } \\
\text { (g) }\end{array}$ & $\begin{array}{l}\text { Gordura } \\
\text { total (g) }\end{array}$ & $\begin{array}{c}\text { Gordura } \\
\text { saturada (g) }\end{array}$ & Fibras (g) & Sódio (mg) \\
\hline \multicolumn{8}{|l|}{ Polpa } \\
\hline $\begin{array}{l}\text { ALMEIDA, } \\
2003\end{array}$ & 26 & 6,4 & 0,5 & 0,2 & 0 & 0,3 & 1 \\
\hline TACO, 2011 & 33 & 8,1 & 0,9 & traços & 0 & 0,1 & traços \\
\hline \multicolumn{8}{|l|}{ Casca } \\
\hline $\begin{array}{l}\text { SANTANA, et } \\
\text { al., } 2005\end{array}$ & 15,18 & 2,19 & 0,93 & 0,3 & 0 & $\begin{array}{c}\text { não } \\
\text { calculado }\end{array}$ & $\begin{array}{c}\text { não } \\
\text { calculado }\end{array}$ \\
\hline $\begin{array}{l}\text { UNESP, } \\
2006\end{array}$ & 14,39 & 1,34 & 0,84 & 0,6 & 0 & $\begin{array}{c}\text { não } \\
\text { calculado }\end{array}$ & $\begin{array}{c}\text { não } \\
\text { calculado }\end{array}$ \\
\hline
\end{tabular}

Como pode ser observado, o valor energético das cascas foi menor que na polpa, e o teor de fibras foi maior naquelas do que nestas. Este fato foi considerado positivo devido ao consumo adequado de fibras reduzirem os riscos de síndrome do intestino irritável, câncer de cólon e trazerem um efeito de saciedade, que pode reduzir riscos de obesidade, além de controlar os níveis de glicose e colesterol no sangue, aumentar o bolo fecal e normalizar a microflora intestinal, entre outros benefícios (RAUPP et al., 1999'; SILVA et al., 2001; CALLEGARO et al., $2005^{9} ;^{10}$; ARAUJO; MENEZES; TOMAZINI, $2009^{11}$ apud MENDES, 2013), se

8 RAUPP, D. S. et al. Composição e propriedades fisiológico - nutritivas de uma farinha rica em fibra insolúvel obtida do resíduo fibroso de fecularia de mandioca. Ciênc. Tecnol. Aliment., Campinas, v. 19, n. 2, maio 1999.

9 CALlegaro, M. G. K. et al. Determinação da fibra alimentar insolúvel, solúvel e total de produtos derivados do milho. Cienc. Tecnol. Aliment.,Campinas, v. 25, n. 2, jun. 2005.

10 SILVA, M. R. et al. Utilização tecnológica dos frutos de jatobá-do-cerrado e de jatobá-da-mata na elaboração de biscoitos fontes de fibra alimentar e isentos de açúcares. Ciênc. Tecnol. Aliment., Campinas, v. 21, n. 2, ago. 2001.

11 ARAUJO, E. M.; MENEZES, H. C.; TOMAZINI, J. M. Fibras solúveis e insolúveis de verduras, tubérculos e canela para uso em nutrição clínica. Ciênc. Tecnol. Aliment., Campinas, v. 29, n. 2, jun. 2009. 
consumidas com frequência. Ressalta-se que o consumo médio dos brasileiros com relação ao teor de fibras é considerado baixo.

Embora a proteína das frutas seja de baixo valor biológico, foram encontradas porções maiores deste nutriente nas cascas do que as presentes na polpa, variando em relação ao autor. Segundo Oliveira e Roman (2013), as proteínas são compostos essenciais à todas as células vivas. Elas formam anticorpos e enzimas que realizam atividades de coagulação e transporte, além de mediar várias reações do corpo humano, como contrações musculares e manutenção da mucosa intestinal. Atuam, também, como atividade enzimática, hormonal, imunológica e transportadora de substâncias, sendo consideradas "construtoras", ou seja, agem na síntese de proteínas do organismo.

Nas análises sensoriais, evidenciou-se que a maior parte dos julgadores era de mulheres jovens, entre 18 e 25 anos. Em média, 58 pessoas participaram de cada análise sensorial, sendo que $89,1 \%$ relataram que consumiam as frutas de cada formulação, porém, somente $47,6 \%$ tinham conhecimento sobre o aproveitamento das cascas e $87,8 \%$ não as consumiam.

As notas da aceitação de cada preparação e suas formulações são apresentadas a seguir, nas Tabelas 6.4, 6.5 e 6.6. Observa-se boa aceitação geral dos produtos elaborados.

Tabela 6.4 Média e desvio-padrão (DP) da aceitação das formulações à base de casca de banana

\begin{tabular}{|c|c|c|c|c|}
\hline & \multicolumn{2}{|c|}{ Bolo de casca banana } & \multicolumn{2}{|c|}{ Farofa de casca de banana } \\
\hline & Média & DP & Média & DP \\
\hline Cor & $8,3^{a}$ & $\pm 1,39$ & $8,2^{a}$ & $\pm 1,41$ \\
\hline Sabor & $8,68^{a}$ & $\pm 1,3$ & $6,78^{b}$ & $\pm 1,93$ \\
\hline Textura & $7,59 a$ & $\pm 1,82$ & $7,58^{a}$ & $\pm 1,63$ \\
\hline Global & $8,43^{a}$ & $\pm 1,34$ & $7,15^{b}$ & $\pm 1,65$ \\
\hline
\end{tabular}

Letras diferentes nas linhas diferem significativamente entre si $(p<0,05)$.

Escala utilizada: 0 - desgostei muitíssimo; 5 - nem gostei, nem desgostei; e 10 - gostei muitíssimo.

Observa-se, na Tabela 6.4, que a aceitação das formulações à base de casca de banana foi boa, mesmo analisando os atributos avaliados. Observa-se que o bolo de banana foi mais bem aceito globalmente e pelo sabor, comparado à farofa de banana. Isso pode se dar pelo fato de o brasileiro ter o hábito associar as receitas com fruta com o sabor doce e não salgado. A cultura brasileira não contempla tanto a comida agridoce como em outros países de cultura oriental.

Segundo Oliveira et al. (2009), que elaboraram cinco formulações com diferentes porcentagens de casca e $\mathrm{pH}$ em doces de banana, sua melhor aceitação foi 
no doce com $20 \%$ da casca, que apresentou os seguintes resultados: cor $(75 \%)$, sabor $(80 \%)$ e textura $(88 \%)$.

Tabela 6.5 Média e desvio-padrão (DP) da aceitação das formulações à base de casca de melancia

\begin{tabular}{ccccc} 
& \multicolumn{2}{c}{ Doce de melancia } & \multicolumn{2}{c}{ Salpicão de melancia } \\
\cline { 2 - 5 } & Média & DP & Média & DP \\
\hline Cor & $7,40^{\mathrm{a}}$ & $\pm 2,1$ & $8,31^{\mathrm{b}}$ & $\pm 1,59$ \\
Sabor & $7,33^{\mathrm{a}}$ & $\pm 1,97$ & $8,71^{\mathrm{b}}$ & $\pm 1,29$ \\
Textura & $7,44^{\mathrm{a}}$ & $\pm 1,89$ & $8,56^{\mathrm{b}}$ & $\pm 1,27$ \\
Global & $7,49^{\mathrm{a}}$ & $\pm 1,95$ & $8,79^{\mathrm{b}}$ & $\pm 1,3$ \\
\hline
\end{tabular}

Letras diferentes nas linhas diferem significativamente entre si $(p<0,05)$.

Escala utilizada: 0 - desgostei muitíssimo; 5 - nem gostei, nem desgostei; e 10 - gostei muitíssimo.

Na Tabela 6.5, verifica-se que a receita salgada da casca de melancia mostrou ser mais aceita em todos os aspectos avaliados. Isso pode se dar pelo fato de que a mesma não apresentou tanto o gosto da casca, como ficou nítido no doce, apesar de a cultura brasileira associar fruta com doce. Esse resultado é de grande importância para mostrar que é possível utilizar frutas em receitas salgadas com ótima aceitação.

Segundo Santana e Oliveira (2005), que elaboraram quatro diferentes formulações de doces com a casca da melancia, o doce em calda com coco foi o mais bem aceito, com cerca de $86 \%$ de aceitação entre adultos.

Tabela 6.6 Média e desvio-padrão (DP) da aceitação das formulações à base de casca de melão

\begin{tabular}{ccccc} 
& \multicolumn{2}{c}{ Doce de melão } & \multicolumn{2}{c}{ Suflê de melão } \\
\cline { 2 - 5 } & Média & DP & Média & DP \\
\hline Cor & $7,6^{\mathrm{a}}$ & $\pm 1,63$ & $7,9^{\mathrm{a}}$ & $\pm 1,51$ \\
Sabor & $8,24^{\mathrm{a}}$ & $\pm 1,63$ & $8,29^{\mathrm{b}}$ & $\pm 1,66$ \\
Textura & $8,08^{\mathrm{a}}$ & $\pm 1,56$ & $7,89^{\mathrm{b}}$ & $\pm 1,72$ \\
Global & $8,23^{\mathrm{a}}$ & $\pm 1,38$ & $8,19^{\mathrm{a}}$ & $\pm 1,51$ \\
\hline
\end{tabular}

Letras diferentes nas linhas diferem significativamente entre si $(p<0,05)$.

Escala utilizada: 0 - desgostei muitíssimo; 5 - nem gostei, nem desgostei; e 10 - gostei muitíssimo.

$\mathrm{Na}$ Tabela 6.6, observa-se que o doce de melão obteve melhor aceitação global, porém o sabor e a textura obtiveram resultados diferenciados. Isso pode ter ocorrido pelo fato de a população preferir ou até mesmo aceitar receitas doces com mais facilidade, devido ao sabor. A textura do suflê foi mais bem qualificada, 
podendo ser assim caracterizada devido à sua maciez e mastigabilidade serem melhor do que a do doce.

Segundo Miguel et al. (2008), que elaboraram quatro formulações à base de melão (doce, compota, geleia e glaceado), os provadores destacaram na geleia, na compota e no melão glaceado, o sabor e a textura agradáveis e, no doce, o sabor muito doce/muito açucarado, o sabor residual e a textura desagradável.

De acordo com Teixeira, Meinert e Barbetta ${ }^{12}$ (1987 apud Braga et al., 2009), para que um produto seja considerado como aceito, em termos de suas propriedades sensoriais, é necessário que obtenha um índice de aceitabilidade mínimo de $70 \%$. Dessa forma, podemos concluir que todas as elaborações preparadas com partes não convencionalmente consumidas foram bem aceitas pelos provadores, conforme Figura 6.2.

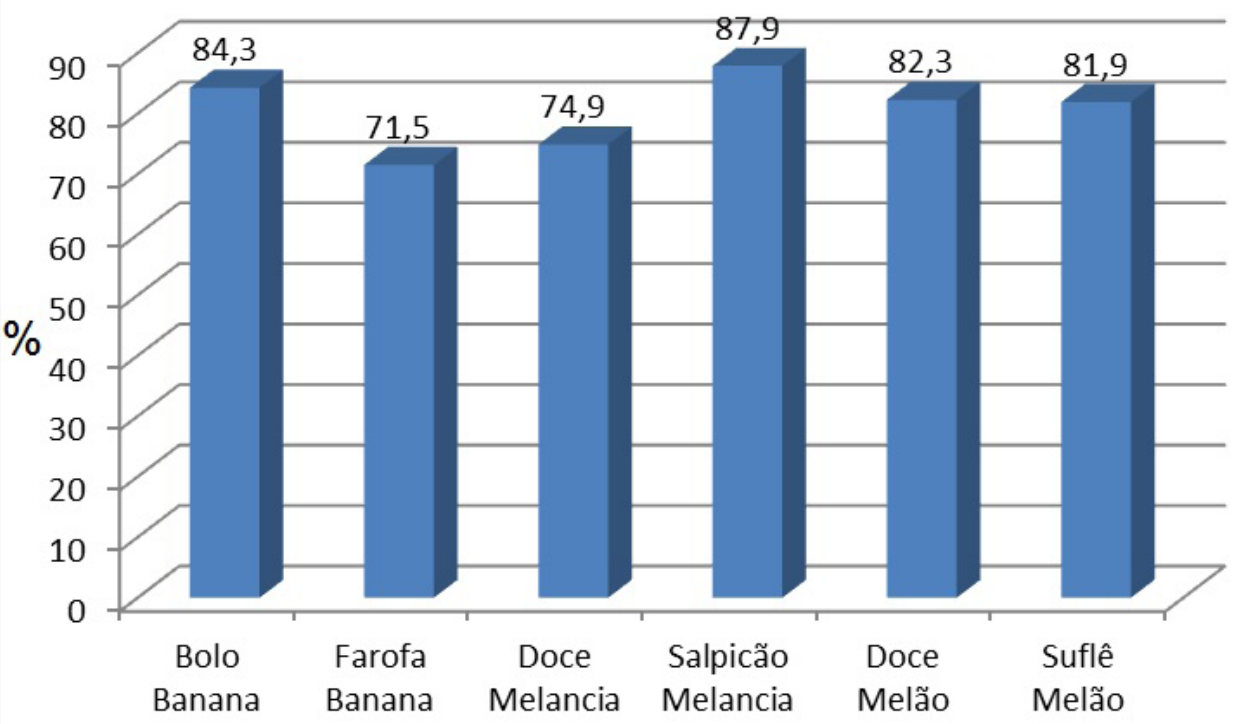

Figura 6.2 Índice de aceitação das formulações analisadas sensorialmente

A informação nutricional de cada produto mostrou que esses têm baixo valor energético, além de baixa quantidade de gorduras, evidenciando a importância que as cascas poderiam ter na alimentação humana se fossem consumidas com maior frequência pela população. Segue a informação nutricional de cada alimento (Tabelas de 6.7 a 6.12).

12 TEIXEIRA, E.; MEINERT, E.; BARBETTA, P. A. Análise sensorial dos alimentos, Florianópolis: Ed. UFSC, 1987.182 p. 
Tabela 6.7 Informação nutricional do bolo de casca de banana

\begin{tabular}{|c|c|c|c|c|c|}
\hline \multicolumn{6}{|c|}{ Informação nutricional } \\
\hline Porção & & 60 g por porçĩ & & & $\%$ VD (*) \\
\hline Valor energético & 400 & $\mathrm{kcal}=$ & 1691 & $\mathrm{~kJ}$ & 20 \\
\hline Carboidrato & & 76,7 & & $g$ & 26 \\
\hline Proteína & & 75,9 & & $g$ & 8 \\
\hline Gordura total & & 7,7 & & $g$ & 14 \\
\hline Gordura saturada & & 1,4 & & $g$ & 7 \\
\hline Gordura trans & & 0 & & $g$ & ** \\
\hline Fibra alimentar & & 1,7 & & $g$ & 7 \\
\hline Sódio & & 43,2 & & $\mathrm{mg}$ & 2 \\
\hline
\end{tabular}

Tabela 6.8 Informação nutricional da farofa de casca de banana

\begin{tabular}{|c|c|c|c|c|c|}
\hline \multicolumn{6}{|c|}{ Informação nutricional } \\
\hline Porção & & g por por & & & $\%$ VD $(*)$ \\
\hline Valor energético & 165 & $\mathrm{kcal}=$ & 696 & $\mathrm{~kJ}$ & 8 \\
\hline Carboidrato & & 29,4 & & $g$ & 10 \\
\hline Proteína & & 3,4 & & $g$ & 5 \\
\hline Gordura total & & 3,8 & & $g$ & 7 \\
\hline Gordura saturada & & 0,7 & & $g$ & 3 \\
\hline Gordura trans & & 0 & & $g$ & ** \\
\hline Fibra alimentar & & 2,4 & & $g$ & 10 \\
\hline Sódio & & 36,3 & & $\mathrm{mg}$ & 2 \\
\hline
\end{tabular}

Tabela 6.9 Informação nutricional do doce da casca de melancia

\begin{tabular}{|c|c|c|c|c|c|}
\hline \multicolumn{6}{|c|}{ Informação nutricional } \\
\hline Porção & & $20 \mathrm{~g}$ por por & & & $\%$ VD (*) \\
\hline Valor energético & 70 & $\mathrm{kcal}=$ & 299 & $k J$ & 4 \\
\hline Carboidrato & & 17,5 & & $g$ & 6 \\
\hline Proteína & & 0,1 & & $g$ & 0 \\
\hline Gordura total & & 0,0 & & $g$ & 0 \\
\hline Gordura saturada & & 0 & & $g$ & 0 \\
\hline Gordura trans & & 0 & & $g$ & ** \\
\hline Fibra alimentar & & 0,0 & & $g$ & 0 \\
\hline Sódio & & 0 & & $\mathrm{mg}$ & 0 \\
\hline
\end{tabular}


Tabela 6.10 Informação nutricional do salpicão da casca de melancia

\begin{tabular}{|c|c|c|c|c|c|}
\hline \multicolumn{6}{|c|}{ Informação nutricional } \\
\hline Porç̃õo & & g por por & & & $\%$ VD $\left({ }^{*}\right)$ \\
\hline Valor energético & 98 & $\mathrm{kcal}=$ & 409 & $\mathrm{~kJ}$ & 5 \\
\hline Carboidrato & & 4,0 & & $g$ & 1 \\
\hline Proteína & & 10,4 & & $g$ & 14 \\
\hline Gordura total & & 4,5 & & $g$ & 8 \\
\hline Gordura saturada & & 0,9 & & $g$ & 4 \\
\hline Gordura trans & & 0 & & $g$ & ** \\
\hline Fibra alimentar & & 0,3 & & $g$ & 1 \\
\hline Sódio & & 219 & & $\mathrm{mg}$ & 9 \\
\hline
\end{tabular}

Tabela 6.11 Informação nutricional do doce da casca de melão

\begin{tabular}{|c|c|c|c|c|c|}
\hline \multicolumn{6}{|c|}{ Informação nutricional } \\
\hline Porção & & $0 \mathrm{~g}$ por po & & & $\% \operatorname{VD}(*)$ \\
\hline Valor energético & 28 & $\mathrm{kcal}=$ & 120 & $\mathrm{~kJ}$ & 1 \\
\hline Carboidrato & & 6,5 & & $g$ & 2 \\
\hline Proteína & & 0,1 & & $g$ & 0 \\
\hline Gordura total & & 0,2 & & $g$ & 0 \\
\hline Gordura saturada & & 0,1 & & $g$ & 1 \\
\hline Gordura trans & & 0 & & $g$ & ** \\
\hline Fibra alimentar & & 0,1 & & $g$ & 0 \\
\hline Sódio & & 0,48 & & $\mathrm{mg}$ & 0 \\
\hline
\end{tabular}

Tabela 6.12 Informação nutricional do suflê da casca de melão

\begin{tabular}{|c|c|c|c|c|c|}
\hline \multicolumn{6}{|c|}{ Informaç̃̃o nutricional } \\
\hline Porção & & $30 \mathrm{~g}$ por po & & & $\%$ VD (*) \\
\hline Valor energético & 59 & $\mathrm{kcal}=$ & 249 & $k$ & 3 \\
\hline Carboidrato & & 7,9 & & $\mathrm{~g}$ & 3 \\
\hline Proteína & & 1,9 & & $g$ & 3 \\
\hline Gordura total & & 2,2 & & $g$ & 4 \\
\hline Gordura saturada & & 0,8 & & $g$ & 4 \\
\hline Gordura trans & & 0 & & $g$ & ** \\
\hline Fibra alimentar & & 0,4 & & $g$ & 1 \\
\hline Sódio & & 155 & & $\mathrm{mg}$ & 6 \\
\hline
\end{tabular}


O bolo de casca de banana, embora nutritivo, foi o único que excedeu seu valor energético se comparado a um bolo convencional, que tem em média 150 calorias, sendo considerado, dessa forma, mais calórico que os produtos similares.

Os resultados foram apresentados para os idosos no Centro de Convivência da Terceira Idade da Zona Leste de Londrina, no dia 27 de maio de 2014, conforme Figura 6.3. As receitas foram levadas prontas para degustação e foi entregue um folder a cada participante.

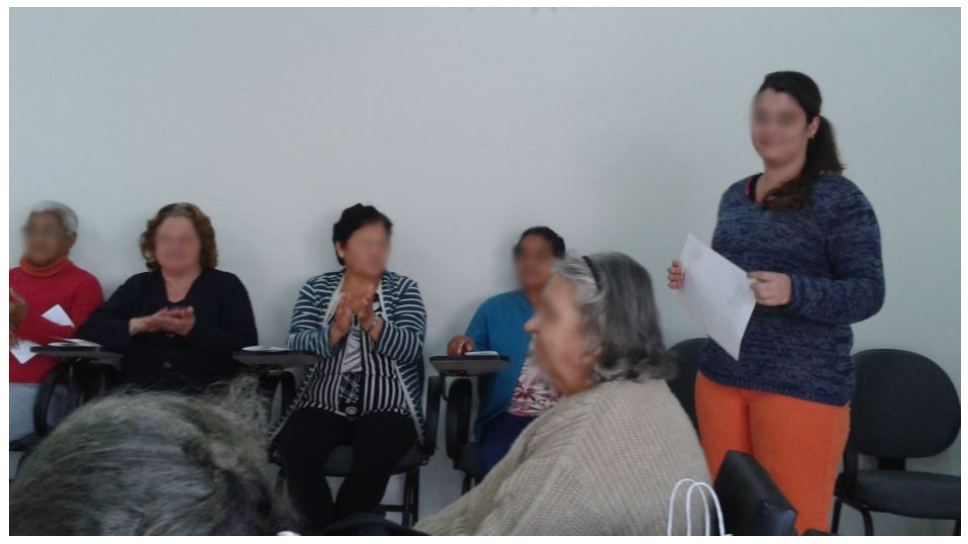

Figura 6.3 Reunião no Centro de Convivência da Terceira Idade de Londrina

O folder elaborado se encontra na Figura 6.4 (parte interna) e na Figura 6.5 (parte externa), sendo esse o material entregue aos idosos participantes do Centro de Convivência.

BOLO DE CASCA DE BANANA Ingredientes: 4 bananas oom casca, 36 xicara
de óleo de soja, 4 ovos, 2 xicaras e meia de cha de farinha de trigo, 3 xicaras de chá de aqúcar. de farinha de trigo, 3 xícaras de chá de
2 xicaras de chá de achooolato em pó.

Modo de preparo: Lave bem as bananas,

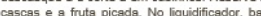
meia xícara de óleo de soja, quatro ovos es cascas sté virar um creme homogêneo. Ex ch́ recipiente, coloque duas xicaras e meia de scúcar, duas xícaras de achocolatado em pó uma coither de cannela. Misture os ingredientes secos com o creme e os pedaços da banan com as màos. Por úlitimo, acrescente uma
colher de chá de fermento em po. Coloque missa em uma assaderia untaga e asse por 40 sçúcar antes de servi-

FAROFA DE CASCA DE BANANA

Ingredientes: 1 xícara (chá) de farinha de Cascos de 3 banones, Cheiroverde os gosto cebola média picada, 1 dente de atho grande, colheres (sops) de óleo, 2 ovos cozidos

Modo de preparo: Em uma panela, faç um refogado com oleo, cebola e alho. Em seguida acrescente as cascas de bananas picadas refogue até que fín mexendo sté que comece a ficar dourgds. Acrescente os ovos cozidos
verde picado, misture bem.

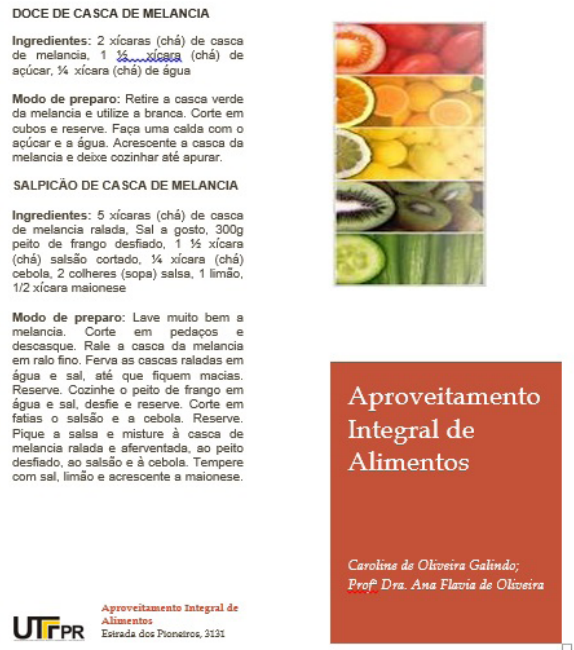

Figura 6.4 Parte interna do folder 


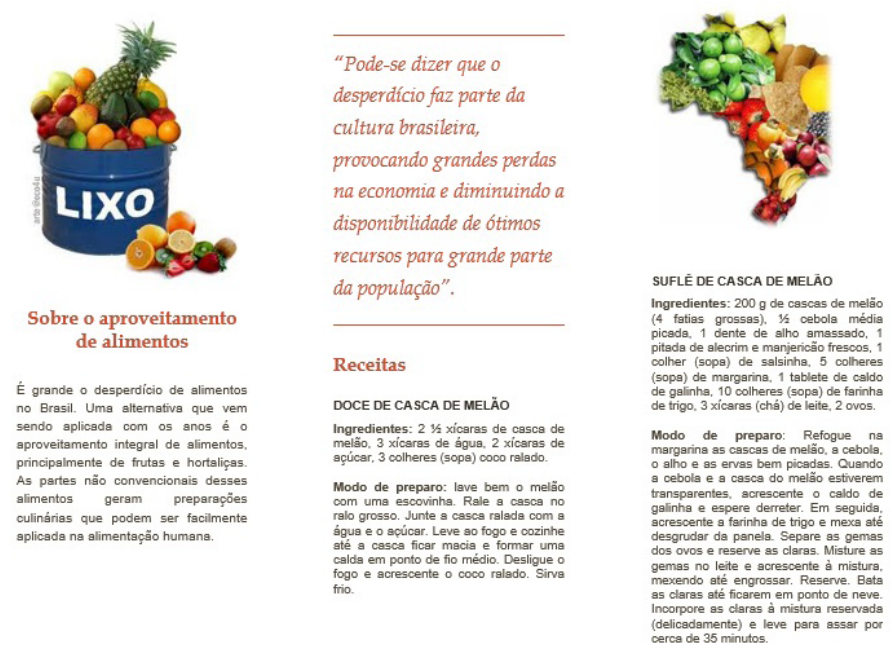

Figura 6.5 Capa do folder (parte externa)

\section{CONCLUSÃO}

Com base no levantamento bibliográfico, as cascas das frutas apresentam maior conteúdo proteico e de fibras quando comparadas à polpa. Com relação ao consumo, embora metade dos entrevistados tivesse conhecimento a respeito da possibilidade do consumo das cascas, pouquíssimos relataram consumi-las.

As receitas elaboradas apresentaram boa aceitação sensorial, mostrando ser possível seu consumo em receitas cotidianas, bem como, com exceção do bolo de casca de banana, os alimentos preparados apresentaram valores energéticos dentro dos padrões para cada tipo de preparação.

O folder foi elaborado para orientar a população, sendo essa etapa do trabalho considerada de extrema importância para divulgar o aproveitamento integral dos alimentos à população atendida pela comunidade universitária.

\section{REFERÊNCIAS}

ALMEIDA, Domingos P. F. Cultura da melancia. Disponível em: $<$ http://www.dalmeida. com/hortnet/Melancia.pdf>. Acesso em: 12 nov. 2013.

BECKER, T. S.; KRÜGER, R. L. Elaboração de barras de cereais com ingredientes alternativos e regionais do Oeste do Paraná. Arq. Ciênc. Saúde UNIPAR., Umuarama, v. 14, n. 3, p. 217-224, set./dez. 2010.

BOL. Receitas sustentáveis aproveitam talos e cascas de alimentos. Disponível em: $<$ http://noticias.bol.uol.com.br/fotos/imagens-do-dia/2013/10/16/receitas-sustentaveisaproveitam-talos-e-cascas-de-alimentos.htm>. Acesso em: 12 ago. 2014. 
BORBA, N. Análise sensorial. Iporá: Instituto Federal de Educação, Ciência e Tecnologia Goiano, 2012.

BORGES, A. L. et al. Banana: instruções práticas de cultivo. Cruz das Almas: Embrapa Mandioca e Fruticultura Tropical, 2006.

BRAGA, L. V. et al. Avaliação sensorial de docinho elaborado com polpa e casca de banana. Instituto Federal de educação, ciência e tecnologia do Ceará: IX ENPPG, IX ENICIT, III SIMPIT, 2009.

BRASIL. Ministério da Saúde. Resolução RDC nº. 360, de 23 de dezembro de 2003. Regulamento Técnico sobre Rotulagem Nutricional de Alimentos Embalados. Diário Oficial da União, Brasília, DF, 26 dez. 2003.

. Ministério da Saúde. Resolução RDC no . 359, de 23 de dezembro de 2003.

Regulamento Técnico de Porções de Alimentos Embalados para fins de Rotulagem Nutricional. Diário Oficial da União, Brasília, DF, 26 dez. 2003.

CHAVES, M. C. V. et al. Caracterização físico-química do suco da acerola. Revista de Biologia e Ciências da Terra, Belo Horizonte, v. 4, n. 2, p. 1-10, 2004.

CODEAGRO - Coordenadoria de Desenvolvimento de Agronegócios. Centro de Segurança Alimentar e Nutricional Sustentável. Diga não ao desperdício. 2007. Disponível em: <http://pt.slideshare.net/Culinaria/livro-de-receitas-diga-no-aodisperdicio-1>. Acesso em: 12 ago. 2014.

DUTCOSKY, S. D. Métodos subjetivos ou afetivos. In: . Análise sensorial de alimentos. 2 ed. Champagnat: Curitiba, 2007. p. 141-152.

FASOLIN, L. H. et al. Biscoitos produzidos com farinha de banana: avaliações química, física e sensorial. Ciênc. Tecnol. Aliment., Campinas, n. 27, v. 3, p. 524-529, jul.-set. 2007. FERREIRA, V. L. P. et al. Análise sensorial: testes discriminativos e afetivos. Campinas: SBCTA, 2000.

GALESKAS, H. et al. A ascensão das classes sociais e o consumo de frutas e hortaliças no Brasil. In: Congresso Brasileiro de Fruticultura, 22, 2012, Bento Gonçalves. Disponível em: <www.congressofruticultura2012.com.br>. Acesso em: 24 jun. 2013. GONDIM, J. A. M. et al. Composição centesimal e de minerais em casca de frutas. Revista de Ciência e Tecnologia de Alimentos. São Paulo, v. 25, n. 4, p. 825 - 827, out./ dez. 2005.

HUMANIDADE SUSTENTÁVEL. Doce de casca de melão. Disponível em: http:// humanidadesustentavel.blogspot.com.br/2009/10/doce-de-casca-de-melao.html. Acesso em 12 ago. 2014.

IBGE. Pesquisa de orçamentos familiares 2008-2009: Avaliação nutricional da disponibilidade domiciliar de alimentos no Brasil. Rio de Janeiro: IBGE, 2010. 54 p. Disponível em: < http://biblioteca.ibge.gov.br/visualizacao/livros/liv47310.pdf>. Acesso em: 4 abr. 2014.

MARANGONI, S. Nem tudo que parece é lixo. Rev. Nutrir. v. 2, n. 15, p. 58-63, out.2009. MATTAR, H. Caderno Temático: a nutrição e o consumo consciente. São Paulo, 2007. Disponível em: <http://www.akatu.org.br>. Acesso em: 05 ago.2013. 
MENDES, B. A. B. Obtenção, caracterização e aplicação de farinha das cascas de abacaxi e de manga. 2013. 78 f. Tese (Mestrado em Engenharia de Alimentos) Universidade Estadual do Sudoeste da Bahia, Itapetinga, 2013.

MIGUEL, A. C. A. et al. Aproveitamento agroindustrial de resíduos sólidos provenientes do melão minimamente processado. Ciênc. Tecnol. Aliment., Campinas, n. 28, v. 3, p. 733-737, jul.-set. 2008.

MONTEIRO, B. A. Valor nutricional de partes convencionais e não convencionais de frutas e hortaliças. 2009. 68f. Dissertação (Mestrado em Agronomia - Energia na Agricultura) - Faculdade de Ciências Agronômicas, Universidade Estadual Paulista "Julio de Mesquita Filho" (UNESP), Botucatu, 2009.

MOREIRA, S. R. et al. Melão (Cucumis melo L.). Disponível em: <http://www. infobibos.com/Artigos/2009_3/melao/index.htm>. Acesso em: 12 nov. 2013.

NASCENTE, A. S. et al. Cultivo de banana em Rondônia. Embrapa. Disponível em: <http://sistemasdeproducao.cnptia.embrapa.br/FontesHTML /Banana/ CultivodaBananaRO/index.htm>. Acesso em: 12 nov. 2013.

NUNES, J. T.; BOTELHO, R. B. A. Aproveitamento integral dos alimentos: qualidade nutricional e aceitabilidade das preparações. 2009. 65f. Monografia (Especialização em Qualidade em Alimentos) - Universidade de Brasília, Brasília, 2009.

OLIVEIRA, L. F. et al. Aproveitamento alternativo da casca do maracujá-amarelo (Passiflora Edulis F. Flavicarpa) para produção de doce em calda. Revista de Ciência de Tecnologia de Alimento, Campinas, v.22, n. 3, p. 259 -262, set./dez. 2002.

- Utilização de casca de banana na fabricação de doces de banana em massa avaliação da qualidade. Alim. Nutr., Araraquara. v. 20, n. 4, p. 581-589, out./dez. 2009. OLIVEIRA, A. F.; ROMAN J. A. Nutrição para tecnologia e engenharia de alimentos. Curitiba: Editora CRV, 2013.

PARK, K. J.; ANTÔNIO, G. C. Análises de materiais biológicos. Campinas: Universidade Estadual de Campinas, 2006.

PEREIRA, R. J. Composição centesimal, aspectos fitoquímicos, atividades antioxidante, hipoglicemiante e antihiperlipidêmica de furtos do gênero Syzygium. Lavras, 2011.

157 p. Tese (Doutorado em Ciência dos Alimentos) - Universidade Federal de Lavras, Lavras, 2011.

SANTANA, A. F., OLIVEIRA, L. F., Aproveitamento da casca de melancia (Curcubita citrullus, Shrad) na produção artesanal de doces alternativos. Alim. Nutr., Araraquara, v. 16, n. 4, p. 363-368, out./dez. 2005.

SANTOS, M. H. O. Desperdício de alimentos e sua interferência no meio ambiente. Enciclopédia Biosfera. Goiânia, n. 5, 2008.

SOUZA, J. C. et al. Qualidade protéica de multimisturas distribuídas em Alfenas, Minas Gerais, Brasil. Revista de Nutrição, Campinas, nov./dez. 2006.

STORCK, C. R. et al. Folhas, talos, cascas e sementes de vegetais: composição nutricional, aproveitamento na alimentação e análise sensorial de preparações. Ciência Rural, Santa Maria, v. 43, n. 3, p. 537-543, mar, 2013. 
TACO. Tabela Brasileira de Composição de Alimentos. UNICAMP: 4. ed. rev. e ampl. Campinas: NEPAUNICAMP, 2011. 161 p.

TELESSAÚDE BRASIL. Receitas de aproveitamento de alimentos. Disponível em: <http://www.telessaudesp.org.br/programa/diabetes/receita-farofa.aspx>. Acesso em: 12 ago. 2014.

TUDO GOSTOSO. Doce de casca de melancia. Disponível em: <http://www.tudogostoso. com.br/receita/32086-doce-de-casca-de-melancia.html>. Acesso em 12 ago. 2014a.

. Salpicão de casca de melancia. Disponível em: <http:/www.tudogostoso.com.br/ receita/1858-salpicao-de-casca-de-melancia.html>. Acesso em: 12 ago. 2014b.

UNESP. O valor do alimento que é jogado fora. Jornal UNESP, n. 213, 2006. Disponível em: <http://www.unesp.br/aci/jornal/213/desperdicio.php>. Acesso em: 02 jul. 2013.

VARGAS, P. F. et al. Qualidade de melão rendilhado (Cucumis melo L.) em função do sistema de cultivo. Ciênc. agrotec., Lavras, v. 32, n. 1, p. 137-142, jan./fev., 2008.

VILLANUEVA, N. D. M. Avaliação do desempenho de quatro métodos de escalonamento em testes sensoriais de aceitação utilizando modelos normais aditivos de análise de variância e mapas internos de preferência. Campinas, 2003. 140 p. Tese (Doutorado em Ciência dos Alimentos e Nutrição), Universidade de Campinas (UNICAMP), Campinas, 2003. 